\title{
Reported in a CBE or AR
}

National Cancer Institute

\section{Source}

National Cancer Institute. Reported in a CBE or AR. NCI Thesaurus. Code C134012.

The specification may be used without prior approval, and was submitted in a changes being effected (CBE) supplement or an annual report (AR). 